\title{
DAMPAK PROGRAM KAWASAN RUMAH PANGAN LESTARI TERHADAP PENDAPATAN DAN PENGELUARAN PANGAN DI KABUPATEN MEMPAWAH
}

\author{
ADE KUSUMA AKBAR ${ }^{1)}$, ABDUL HAMID A. YUSRA ${ }^{2)}$, \\ YOHANA S. KUSUMA DEWI ${ }^{2)}$
}

\author{
1) Alumni Magister Manajemen Agribisnis Fakultas Pertanian Universitas \\ Tanjungpura Pontianak. \\ 2) Staf Pengajar Fakultas Pertanian Universitas Tanjungpura Pontianak
}

\begin{abstract}
Research objective is to analyses the impact of sustainable food house area (KRPL) of household income, comestible expenses, and consumption pattern in the village which receive KRPL aid. Research was conducted in Mempawah Regency West Kalimantan Province with survey methods by means of direct observation with sample and location which is pre-determined and selected deliberately. Data is collected by means of interview and using questioner. The result of this research show that there is differences in the income of household of KRPL aid receivers which is IDR 3.267.015 /month compared to non KRPL aid receivers which is IDR 2.851 .282 /month. KRPL contribution to household income difference is IDR 99.125 /month, equal to 3,03\% of total household income. While in terms of comestible expenses, research shows that percentage of total income spent for comestible is 59,44\% for KRPL aid receivers and 59,48\% non KRPL aid receivers, there is no significant difference between KRPL aid receivers and non KRPL aid receivers. These numbers indicate that comestible expenses, in low income household, tend to become major component of total expenses.
\end{abstract}

Keywords: Comestible expenses; Household income; KRPL.

\section{PENDAHULUAN}

Salah satu komitmen pemerintah dalam mewujudkan diversifikasi pangan berbasis sumberdaya lokal dengan membudidayakan tananam di pekarangan. melalui Program Kawasan Rumah Pangan Lestari (KRPL). Tujuan KRPL adalah sebagai upaya untuk menuju kecukupan dan kemandirian pangan rumah tangga, menekan biaya pengeluaran rumah tangga dan menjadi tumpuan untuk mengantisipasi perubahan alih fungsi lahan pertanian dengan pemanfaatan pekarangan.

Struktur pengeluaran rumah tangga dan tingkat pendapatan merupakan salah satu indikator untuk melihat tingkat kesejahteraan rumah tangga. Rumah tangga dengan pangsa pengeluaran pangan yang tinggi tergolong rumah tangga dengan tingkat kesejahteraan rendah relatif dibanding rumah tangga dengan proporsi pengeluaran untuk pangan yang rendah. Peningkatan pendapatan per kapita akan mencerminkan adanya perbaikan dalam kesejahteraan masyarakat dan sangat berpengaruh terhadap pola konsumsi pangan secara umum.

Kabupaten Mempawah merupakan salah satu kabupaten yang mendapatkan bantuan Program Optimalisasi Pemanfaatan Pekarangan melalui konsep Kawasan Rumah Pangan Lestari (KRPL). Data pada tahun 2012 
menunjukkan bahwa pekarangan di Kabupaten Mempawah luasnya mencapai 9.221 hektar namun belum dimanfaatkan secara optimal untuk ketahanan pangan (BPS Kabupaten Pontianak, 2014). Masyarakat di Kabupaten Mempawah pada saat sebelum menerapkan KRPL, sebagian besar belum melakukan optimalisasi pekarangan. Masyarakat hanya menanam tanaman turun-menurun atau sudah ada seperti pohon mangga, pohon pisang, pohon jeruk, dan lain-lain. Tanaman sayuran sangat jarang diusahakan padahal ini sangat penting untuk digalakkan dalam kebutuhan pangan dan pemenuhan gizi.

Seiring dengan perkembangan KRPL, kehidupan masyarakat di sekitar desa penerima bantuan program KRPL mengalami perubahan baik dari aspek sosial, ekonomi, maupun lingkungan. Program KRPL di Kabupaten Mempawah diharapkan dapat memberikan manfaat bagi masyarakat baik bagi pelaku KRPL maupun lingkungan kawasan di sekitarnya. Bagi pelaku KRPL, kegiatan ini dapat memberikan sumbangan pangan untuk dikonsumsi bagi keluarga, menghemat pengeluaran keluarga dalam memenuhi pangan sehari-hari dan terjadinya diversifikasi konsumsi pangan pada rumah tangga pelaku KRPL. Sedangkan bagi lingkungan kawasan, kegiatan ini dapat membuat suasana asri dan lingkungan lebih nyaman.

Penelitian ini bertujuan untuk mengevaluasi KRPL di Kabupaten Mempawah dilihat dari dampak yang ditimbulkannya. Secara lebih rinci maka tujuan dari penelitian ini adalah untuk menganalisis dampak program KRPL terhadap peningkatan pendapatan, dan penurunan proporsi pengeluaran pangan di desa penerima bantuan KRPL.

\section{METODE PENELITIAN}

Lokasi penelitian di desa Sungai Bundung Laut, Pasir Palembang, Galang, Peniraman, Peniti Dalam I, Jungkat, Pak Utan dan Amawang di Kabupaten Mempawah. Peserta KRPL merupakan petani yang tergabung Kelompok Wanita Tani yang berjumlah 30 orang setiap desa penerima bantuan program KRPL tahun 2013. Sampel dipilih secara purposive sesuai kriteria 1)Mata pencarian utama kepala keluarga adalah petani 2) Jumlah anggota keluarga maksimal 5 orang 3)usia responden sampel termasuk dalam usia produktif $15-64$ tahun. Penentuan sampel menggunakan rumus slovin berjumlah 72 responden, setiap desa berjumlah 9 responden. Kelompok tani kontrol adalah petani dari Desa Sengkubang dan Desa Kecurit. Pertmbangan pemilihan kontrol adalah 1)Kesamaan karakteristik mata pencaharian masyarakat yang menjadi sampel kontrol dengan sampel yang mendapat program KRPL, yaitu sebagian besar mata pencahariannya adalah pertanian, 2)Petani sampel kontrol tidak/belum pernah menerima program KRPL.

Jenis data yang yang diambil adalah data primer dan data sekunder. Data primer diperoleh melalui kuisioner sedangkan data sekunder merupakan data pendukung yang diperoleh melalui studi pustaka.

Analisis Pendapatan Rumah Tangga

Penghitungan analisis pendapatan petani menggunakan Rahim dan Astuti (2008) 


$$
\mathrm{Y}=\sum_{i=1}^{n}(\mathrm{P})_{\mathrm{i}}+\sum_{l=1}^{m}(\mathrm{NP})_{\mathrm{j}}
$$

Keterangan :

$\mathrm{Y}=$ total pendapatan rumah tangga $(\mathrm{Rp} / \mathrm{bulan})$

$\mathrm{P} \quad=$ pendapatan rumah tangga dari kegiatan usahatani $(\mathrm{Rp} / \mathrm{bulan})$

$\mathrm{NP} \quad=$ pendapatan rumah tangga dari kegiatan non usahatani $(\mathrm{Rp} / \mathrm{bulan})$

$\mathrm{i}=1 \ldots \mathrm{n}=$ usahatani di beberapa sub sektor dari anggota rumah tangga

$\mathrm{j}=1 \ldots \mathrm{n}=$ non usahatani dari berbagai kegiatan anggota rumah tangga

\section{Analisis Pengeluaran Pangan Rumah Tangga}

Analisis pengeluaran pangan rumah tangga berdasarkan proporsi pengeluaran pangan (Ilham dan Sinaga, 20017) dengan rumus sebagai berikut :

$$
\mathrm{PF}=\frac{\mathrm{PP}}{\mathrm{TP}} \times 100 \%
$$

Keterangan :

$\mathrm{PF}=$ Proporsi Pengeluaran Pangan $(\%)$

$\mathrm{PP}=$ Pengeluaran untuk Pangan Rumah Tangga Petani (Rp/bulan)

$\mathrm{TP}=$ Total Pengeluaran Rumah Tangga Petani (Rp/bulan)

(Ilham dan Sinaga, 2007)

\section{Analisis Statistik}

Analisis dampak program KRPL menggunakan Independent Sample t Test. Variabel yang akan diukur adalah tingkat pendapatan rumah tangga, proporsi pengeluaran pangan rumah tangga. Data dinyatakan memiliki varian yang sama (equal variance) bila F-Hitung < F-Tabel, dan sebaliknya, varian data dinyatakan tidak sama (unequal variance) bila F-Hitung > F-Tabel (https://freelearningji.wordpress.com/2013/04/06/uji-t-dua-sampel/, 2013).

Hipotesis yang akan diuji adalah perbedaan nilai rata-rata pendapatan rumah tangga per bulan dan proporsi pengeluaran pangan per bulan Uji $t$ dihitung berdasarkan hipotesis dengan kriteria uji :

1. $\mathrm{H}_{1}: \mathrm{X}_{1} \neq \mathrm{X}_{2}$ (ada perbedaan nilai variabel antara kelompok aksi dengan kelompok kontrol)

$\mathrm{H}_{0}: \mathrm{X}_{1}=\mathrm{X}_{2} \quad$ (tidak ada perbedaan nilai variabel antara kelompok aksi dengan kelompok kontrol)

Dimana:

$\mathrm{X}_{1}=$ pendapatan rumah tangga/proporsi pengeluaran pangan.

$\mathrm{X}_{2}=$ pendapatan rumah tangga/proporsi pengeluaran pangan .

2. Nilai $t$ dibandingkan dengan harga $t$ tabel dengan taraf kesalahan sebesar $5 \%$.

3. $t$ hitung lebih kecil dari $t$ tabel $\left(t\right.$-hit $\leq t$ tabel) maka $\mathrm{H}_{0}$ "diterima". jika $t$ hitung lebih besar dari $t$ tabel ( $t$-hit $>t$ tabel) maka $\mathrm{H}_{1}$ "diterima" (Sugiyono, 2009).

\section{HASIL DAN PEMBAHASAN}

\section{Analisis Pendapatan Rumah Tangga}

Pendapatan rumah tangga merupakan sejumlah uang yang didapat oleh masing-masing anggota rumah tangga dari pekerjaan yang dilakukan dalam satu bulan baik berupa pendapatan usaha tani maupun pendapatan non usaha tani yang dihitung dalam satuan rupiah/bulan (Soekartawi, 2002). 
Pendapatan usahatani pada penelitian ini terdiri dari pendapatan usahatani yang berasal dari pekarangan dan pendapatan usahatani yang berasal dari non pekarangan. Pendapatan usahatani dari pekarangan merupakan pendapatan yang diperoleh dari tanaman yang dibudidayakan melalui program KRPL, sedangkan pendapatan usahatani non pekarangan merupakan pendapatan dari suami, istri ataupun anggota keluarga dari sektor pertanian baik sebagai petani penggarap, sewa, bagi hasil dan buruh tani yang diperoleh dari luar pekarangan. Pendapatan anggota keluarga seperti wirausaha, berdagang, beternak, kuli bangunan, staff desa dan lain-lain termasuk kedalam pendapatan non usahatani.

Tabel 1. Rata-rata Pendapatan Penerima KRPL dan Non Penerima KRPL Kabupaten Mempawah

\begin{tabular}{|c|c|c|c|c|c|c|c|c|}
\hline \multirow[b]{2}{*}{ No } & \multirow[b]{2}{*}{ Desa } & \multicolumn{2}{|c|}{$\begin{array}{c}\text { Pendapatan } \\
\text { KRPL }\end{array}$} & \multicolumn{2}{|c|}{$\begin{array}{c}\text { Pendapatan } \\
\text { Usahatani }\end{array}$} & \multicolumn{2}{|c|}{$\begin{array}{c}\text { Pendapatan Non } \\
\text { Usahatani }\end{array}$} & \multirow{2}{*}{$\begin{array}{c}\text { Total } \\
\text { Pendapatan } \\
\text { (Rp/bulan) }\end{array}$} \\
\hline & & $\begin{array}{l}\text { Rata-rata } \\
\text { (Rp/bulan) }\end{array}$ & $\%$ & $\begin{array}{c}\text { Rata-rata } \\
\text { (Rp/Ha/ } \\
\text { bulan) }\end{array}$ & $\%$ & $\begin{array}{l}\text { Rata-rata } \\
\text { (Rp/bulan) }\end{array}$ & $\%$ & \\
\hline 1 & 2 & 3 & 4 & 5 & 6 & 7 & 8 & 9 \\
\hline A & Penerima KRPL & & & & & & & \\
\hline 1 & Sungai Bundung & 126.333 & 4,15 & 1.957 .846 & 64,35 & 958.333 & 31,50 & 3.042 .513 \\
\hline 2 & Laut & 67.778 & 2,07 & 1.552 .401 & 47,31 & 1.661 .111 & 50,62 & 3.281 .290 \\
\hline 3 & Pasir Palembang & 76.667 & 2,41 & 1.861 .726 & 58,49 & 1.244 .444 & 39,10 & 3.182 .837 \\
\hline 4 & Peniraman & 96.111 & 2,71 & 1.964 .689 & 55,35 & 1.488 .889 & 41,94 & 3.549 .689 \\
\hline 5 & Galang & 76.667 & 2,37 & 2.001 .482 & 62,00 & 1.150 .000 & 35,62 & 3.228 .149 \\
\hline 6 & Pak Utan & 170.556 & 5,06 & 1.960 .335 & 58,17 & 1.238 .889 & 36,76 & 3.369 .780 \\
\hline 7 & Amawang & 83.889 & 2,52 & 1.852 .251 & 55,71 & 1.388 .889 & 41,77 & 3.325 .029 \\
\hline 8 & $\begin{array}{l}\text { Peniti Dalam I } \\
\text { Jungkat }\end{array}$ & 95.000 & 3,01 & 1.928 .497 & 61,09 & 1.133 .333 & 35,90 & 3.156 .830 \\
\hline & Jumlah & 793.000 & & 15.079 .228 & & 10.263 .889 & & 31.774.272 \\
\hline & Rata-rata & 99.125 & $\mathbf{3 , 0 3}$ & 1.884 .904 & 57,69 & 1.282 .986 & 39,27 & 3.267 .015 \\
\hline B & $\begin{array}{l}\text { Non Penerima } \\
\text { KRPL }\end{array}$ & - & - & 1.926 .209 & 63,77 & 1.094 .444 & 36,23 & 3.020 .653 \\
\hline $\begin{array}{l}1 \\
2\end{array}$ & $\begin{array}{l}\text { Sengkubang } \\
\text { Kecurit }\end{array}$ & - & - & 1.448 .578 & 54,01 & 1.233 .333 & 45,99 & 2.681 .912 \\
\hline & Jumlah & - & - & 3.374.787 & & 3.374.787 & & 5.702 .565 \\
\hline & Rata-rata & - & - & 1.687 .393 & 59,18 & 1.687 .393 & 40,82 & 2.851 .282 \\
\hline
\end{tabular}

Sumber : Data Primer, 2015

Hasil pendapatan usahatani penerima KRPL sebesar Rp. 1.884.903,ha/bulan atau 57,69\% dari pendapatan rumah tangga, sedangkan kelompok non penerima KRPL sebesar Rp. 1.687.393,- ha/bulan atau 59,18\% dari total pendapatan rumah tangga (Tabel 1). Hasil pendapatan non usahatani penerima KRPL sebesar Rp. 1.282.986,- /bulan atau 39,27\% dari pendapatan rumah tangga, sedangkan kelompok non penerima KRPL sebesar Rp. 1.163.889,- /bulan atau $40,82 \%$ dari total pendapatan rumah tangga.

Besarnya persentase pendapatan non usahatani yang lebih tinggi dari persentase pendapatan usahatani di responden penerima KRPL dan non penerima KRPL, disebabkan karena pendapatan usahatani hanya berasal dari sektor pertanian yang biasanya hanya diperoleh dari kepala rumah tangga, sedangkan pendapatan non usahatani diperoleh semua anggota rumah tangga dan dari berbagai sektor pekerjaan. 
Rata-rata kontribusi KRPL terhadap pendapatan rumah tangga sebesar Rp. 99.125,- /bulan atau menyumbang 3,03\% dari keseluruhan pendapatan rumah tangga. Persentase kontribusi pendapatan kegiatan KRPL yang masih kecil dikarenakan kegiatan KRPL diterapkan pada lahan pekarangan yang relatif sempit dan fokus kegiatan tidak untuk kegiatan komersil namun untuk kebutuhan rumah tangga, sehingga budidaya yang dilakukan hanya sebatas luas pekarangan rumah tangga.

Tabel 2. Independent Sample t Test Pendapatan Rumah Tangga

\begin{tabular}{lcc}
\hline \multicolumn{1}{c}{ Uraian } & $\begin{array}{c}\text { Penerima } \\
\text { KRPL }\end{array}$ & $\begin{array}{c}\text { Non Penerima } \\
\text { KRPL }\end{array}$ \\
\hline \multicolumn{1}{c}{1} & 2 & 3 \\
\hline Mean (Rp/Bulan) & 3.167 .890 & 2.851 .282 \\
Variance & 373002572459,01 & 233697136916,35 \\
Observations & 72 & 18 \\
Pooled Variance & 346091295138,27 & \\
Hypothesized Mean Difference & 0 & \\
df & 88 & \\
t Stat & 2,68 & \\
t Critical one-tail & 1,66 & \\
t Critical two-tail & 1,99 & \\
\hline
\end{tabular}

Sumber : Data Primer (diolah menggunakan Microsoft Office Excell), 2015

Hasil Uji t menunjukkan bahwa nilai t-tabel yang diperoleh adalah 1,99 sedangkan nilai t-hitung sebesar 2,68 sehingga t-hitung $>\mathrm{t}$ tabel. Menurut kriteria uji, jika t-hitung $>\mathrm{t}$ tabel pada taraf nyata 5\% $(\alpha=0,05)$ maka $\mathrm{H}_{1}$ diterima. Kesimpulan hasil pengujian diperoleh bahwa ada perbedaan pendapatan rumah tangga penerima KRPL dan pendapatan rumah tangga non penerima KRPL.

Salah satu tujuan utama yang terkait dengan pelaksanaan program KRPL adalah peningkatan kesejahteraan petani yang dinilai dari peningkatan pendapatan petani. Hasil penelitian menunjukkan bahwa rumah tangga penerima KRPL di Kabupaten Mempawah mengalami peningkatan pendapatan walaupun masih kecil, namun hal tersebut merupakan potensi dan dijadikan dasar agar program KRPL di masa mendatang dapat terus dilaksanakan dan ditingkatkan.

\section{Analisis Pengeluaran Pangan Rumah Tangga}

Pengeluaran rumah tangga adalah biaya yang dikeluarkan untuk konsumsi semua anggota rumah tangga. Konsumsi rumah tangga digolongkan menjadi 2 yaitu konsumsi pangan dan non pangan tanpa memperhatikan asal barang dan terbatas pada pengeluaran untuk kebutuhan rumah tangga saja, tidak termasuk pengeluaran untuk usaha.

Besarnya pengeluaran untuk pangan rumah tangga penerima KRPL adalah Rp 1.184.443,- dan pengeluaran non pangan sebesar Rp 808.281,-- sehingga ratarata pengeluaran rumah tangga sebesar Rp 1.992.724,-. Pengeluaran untuk pangan rumah tangga non penerima KRPL adalah Rp. 1.101.700,- dan pengeluaran non pangan sebesar Rp. 657.248,- sehingga rata-rata pengeluaran rumah tangga sebesar Rp. 1.758.948,- (Tabel 3).

Pengeluaran pangan terbesar adalah untuk padi-padian, pada rumah tangga penerima KRPL mencapai 34,98\%, sedangkan rumah tangga non penerima KRPL sebesar 36,08\%. Kelompok pangan padi-padian meliputi beras, jagung, tepung beras, tepung jagung, tepung terigu dan jenis produk dari padi-padian. Besarnya 
pengeluaran untuk padi-padian karena padi/beras merupakan makanan pokok bagi setiap rumah tangga petani, selain itu tepung beras dan tepung terigu dapat digunakan untuk bahan-bahan pembuat lauk-pauk.

Tabel 3. Rata-rata Pengeluaran Rumah Tangga Penerima KRPL Dan Non Penerima KRPL Kabupaten Mempawah

\begin{tabular}{|c|c|c|c|c|c|}
\hline \multirow{2}{*}{ No } & \multirow{2}{*}{ Jenis Pengeluaran } & \multicolumn{2}{|c|}{$\begin{array}{l}\text { Penerima } \\
\text { KRPL }\end{array}$} & \multicolumn{2}{|c|}{$\begin{array}{c}\text { Non Penerima } \\
\text { KRPL }\end{array}$} \\
\hline & & $\begin{array}{l}\text { Rata-rata } \\
\text { (Rp/bulan) }\end{array}$ & $\begin{array}{c}\text { Persen } \\
(\%)\end{array}$ & $\begin{array}{l}\text { Rata-rata } \\
\text { (Rp/bulan) }\end{array}$ & $\begin{array}{c}\text { Persen } \\
(\%)\end{array}$ \\
\hline 1 & 2 & 3 & 4 & 5 & 6 \\
\hline \multirow[t]{15}{*}{1} & Pengeluaran Pangan & & & & \\
\hline & a. Padi-padian & 414.327 & 34,98 & 397.500 & 36,08 \\
\hline & b. Umbi-umbian & 19.333 & 1,63 & 15.633 & 1,42 \\
\hline & c. Ikan & 131.563 & 11,11 & 104.900 & 9,52 \\
\hline & d. Daging & 87.200 & 7,36 & 68.431 & 6,21 \\
\hline & e. Telur dan susu & 84.786 & 7,16 & 85.667 & 7,78 \\
\hline & f. Sayur-sayuran & 97.821 & 8,26 & 78.556 & 7,13 \\
\hline & g. Kacang-kacangan & 17.500 & 1,48 & 17.600 & 1,60 \\
\hline & h. Buah-buahan & 34.357 & 2,90 & 35.633 & 3,23 \\
\hline & i. Minyak dan lemak & 52.536 & 4,44 & 61.724 & 5,60 \\
\hline & j. Bahan minuman & 87.127 & 7,36 & 82.700 & 7,51 \\
\hline & k. Bumbu-bumbuan & 63.692 & 5,38 & 61.556 & 5,59 \\
\hline & 1. Konsumsi lain & 76.432 & 6,45 & 78.100 & 7,09 \\
\hline & m. Makanan jadi & 17.769 & 1,50 & 13.700 & 1,24 \\
\hline & Jumlah & 1.184 .443 & 100,00 & 1.101 .700 & 100.00 \\
\hline \multirow[t]{9}{*}{2} & Pengeluaran Non Pangan & & & & \\
\hline & a. Fasilitas rumah & 193.884 & 23,99 & 176.753 & 26,89 \\
\hline & b. Barang dan jasa & 291.930 & 36,12 & 225.925 & 34,37 \\
\hline & c. Sandang & 49.262 & 6,09 & 33.522 & 5,10 \\
\hline & d. Barang tahan lama & 10.242 & 1,27 & 13.333 & 2,03 \\
\hline & e. Pajak dan asuransi & 19.338 & 2,39 & 16.048 & 2,44 \\
\hline & f. Keperluan sosial dll & 243.625 & 30,14 & 191.667 & 29,16 \\
\hline & Jumlah & 808.281 & 100,00 & 657.248 & 100,00 \\
\hline & Total & 1.992.724 & 100,00 & 1.758 .948 & 100,00 \\
\hline
\end{tabular}

Sumber : Data Primer, 2015

Pengeluaran non pangan terdiri dari fasilitas rumah tangga, barang dan jasa, sandang, barang tahan lama, pajak dan asuransi, dan lain-lain. Pengeluaran non pangan terbesar rumah tangga penerima KRPL adalah barang dan jasa yaitu $36,12 \%$, sedangkan pada rumah tangga non penerima KRPL sebesar 34,37\% dari pengeluaran non pangan. Pengeluaran untuk aneka barang dan jasa meliputi sabun mandi, sabun cuci, pasta gigi, sikat gigi, shampoo, ongkos transportasi, bensin, perawatan kendaraan, biaya kesehatan, biaya pendidikan, jajan anak dan lain-lain. Pengeluaran pada golongan ini tinggi karena meliputi barang yang dibutuhkan dan dipergunakan setiap hari oleh seluruh anggota rumah tangga. Selain itu untuk transportasi, umumnya tiap rumah tangga mempunyai kendaraan sendiri, sehingga membutuhkan bensin untuk bahan bakarnya, sehingga menambah pengeluaran pada golongan ini. 
Tabel 4. Proporsi Pengeluaran Rumah Tangga Penerima KRPL Dan Non Penerima KRPL Kabupaten Mempawah

\begin{tabular}{|c|c|c|c|c|c|c|c|}
\hline \multirow[b]{2}{*}{ No } & \multirow[b]{2}{*}{ Desa } & \multicolumn{2}{|c|}{$\begin{array}{l}\text { Pengeluaran } \\
\text { Pangan }\end{array}$} & \multicolumn{2}{|c|}{$\begin{array}{l}\text { Pengeluaran } \\
\text { Non Pangan }\end{array}$} & \multicolumn{2}{|c|}{$\begin{array}{c}\text { Total } \\
\text { Pengeluaran }\end{array}$} \\
\hline & & $\begin{array}{c}\text { Rata-rata } \\
\text { (Rp/bulan } \\
\text { /kapita) }\end{array}$ & $\begin{array}{c}\text { Persen } \\
(\%)\end{array}$ & $\begin{array}{c}\text { Rata-rata } \\
\text { (Rp/bulan/ } \\
\text { kapita) }\end{array}$ & $\begin{array}{c}\text { Persen } \\
(\%)\end{array}$ & $\begin{array}{c}\text { Rata-rata } \\
\text { (Rp/bulan } \\
\text { /kapita) }\end{array}$ & $\begin{array}{c}\text { Persen } \\
(\%)\end{array}$ \\
\hline 1 & 2 & 3 & 4 & 5 & 6 & 7 & 8 \\
\hline \multicolumn{8}{|l|}{$\mathbf{A}$} \\
\hline 1 & Sungai Bundung Laut & 279.088 & 58,24 & 200.144 & 41,76 & 479.232 & 100,00 \\
\hline 2 & Pasir Palembang & 367.019 & 60 & 239.635 & 39,53 & 606.654 & 100,00 \\
\hline 3 & Peniraman & 245.423 & & 171.623 & 41,15 & 417.046 & 100,00 \\
\hline 4 & Galang & 270.208 & 58,93 & 188 & 41 , & 458.556 & 100,00 \\
\hline 5 & Pak Utan & 253.942 & 58,01 & 183 & 41, & 437.764 & 100,00 \\
\hline 6 & Ama & 234.997 & 59,83 & 157.748 & 40,17 & 392.745 & 100,00 \\
\hline 7 & Dalam I & 322.942 & 59,15 & 223.022 & 40,85 & 545.964 & 100,00 \\
\hline \multirow[t]{2}{*}{8} & Jungkat & 192.075 & 61,10 & 122.281 & 38,90 & 314.356 & 100,00 \\
\hline & Rata-rata & 270.712 & 59,30 & 185.828 & 40,70 & 456.540 & 100,00 \\
\hline \multicolumn{8}{|l|}{ B } \\
\hline 1 & Sengkubang & 447.609 & 59,58 & 303.718 & 40,42 & 751.327 & 100,00 \\
\hline \multirow[t]{2}{*}{2} & & 252.339 & 59,29 & 173 & 40,71 & 425.580 & 100,00 \\
\hline & Rata-rata & 349.974 & 59,47 & 238.479 & 40,53 & 588.453 & 100,00 \\
\hline
\end{tabular}

Sumber : Data Primer, 2015

Proporsi pengeluaran merupakan persentase banyaknya pengeluaran dibanding besarnya pengeluaran total. Pengeluaran total merupakan pengeluaran untuk konsumsi pangan ditambah pengeluaran untuk non pangan. Besarnya ratarata pengeluaran total untuk rumah tangga penerima KRPL adalah Rp 456.540,bulan/kapita, yang meliputi pengeluaran untuk pangan sebesar Rp 270.712,- dan untuk pengeluaran non pangan sebesar Rp 185.828,-. Sedangkan pengeluaran total untuk rumah tangga non penerima KRPL adalah Rp 588.453,- bulan/kapita, yang meliputi pengeluaran untuk pangan sebesar Rp 349.974,- dan untuk pengeluaran non pangan sebesar Rp 238.479,- (Tabel 4). Perbedaan jumlah anggota keluarga menjadi salah satu faktor yang mempengaruhi proporsi pengeluaran pangan dalam rumah tangga. Semakin banyak anggota keluarga dalam rumah tangga akan mempengaruhi besar kecilnya proporsi pengeluaran rumah tangga.

Proporsi pengeluaran pangan rumah tangga non penerima KRPL hampir sama dengan rumah tangga penerima KRPL yaitu 59,48\% berbanding 59,44\%, angka tersebut menunjukkan bahwa pengeluaran pangan masih mengambil lebih besar pengeluaran rumah tangga, ini berarti tingkat kesejahteraan rumah tangga penerima KRPL maupun non penerima KRPL masih rendah. Semakin tinggi proporsi pengeluaran pangan berarti tingkat kesejahteraan rumah tangga semakin rendah.

Tabel 5 menunjukkan bahwa nilai t-tabel yang diperoleh adalah 2,01, sedangkan nilai t-hitung sebesar 0,25 sehingga t-hitung $<\mathrm{t}$ tabel. Menurut kriteria uji, jika t-hitung $\leq \mathrm{t}$ tabel pada taraf nyata 5\% $(\alpha=0,05)$ maka $\mathrm{H}_{0}$ diterima. Kesimpulan hasil pengujian diperoleh bahwa tidak ada perbedaan proporsi pengeluaran pangan rumah tangga penerima KRPL dan non penerima KRPL. 
Tabel 5. Independent Sample t Test Proporsi Pengeluaran Pangan

\begin{tabular}{lcc}
\hline \multicolumn{1}{c}{ Uraian } & $\begin{array}{c}\text { Penerima } \\
\text { KRPL }\end{array}$ & $\begin{array}{c}\text { Non Penerima } \\
\text { KRPL }\end{array}$ \\
\hline \multicolumn{1}{c}{$l$} & 2 & 3 \\
\hline Mean (\%) & 59,57 & 59,42 \\
Variance & 0,0011 & 0,0004 \\
Observations & 72 & 18 \\
Hypothesized Mean Difference & 0 & \\
df & 45 & \\
t Stat & 0,25 & \\
P(T<=t) one-tail & 0,40 & \\
t Critical one-tail & 1,68 & \\
P(T<=t) two-tail & 0,80 & \\
t Critical two-tail & 2,01 & \\
\hline
\end{tabular}

Sumber : Data Primer (diolah menggunakan Microsoft Office Excell), 2015

Pendapatan rumah tangga penerima KRPL dan non penerima KRPL yang masih tergolong rendah atau dibawah Rp 5.000.000/bulan menyebabkan proporsi pengeluaran pangan rumah tangga KRPL dan rumah tangga non KRPL menjadi tidak berbeda. Rumah tangga dengan tingkat pendapatan rendah cenderung menggunakan anggaran rumah tangganya untuk memenuhi kebutuhan pangan keluarganya. Dalam kondisi pendapatan terbatas, kebutuhan makanan didahulukan, sehingga pada kelompok masyarakat berpendapatan rendah akan terlihat bahwa lebih dari 50\% pendapatannya digunakan untuk membeli makanan. Hal tersebut selaras dengan penelitian Ilham dan Bonar (2007), Individu dengan pendapatan rendah akan menggunakan pendapatannya untuk belanja pangan sebesar 50\%. individu dengan pendapatan tinggi akan memenuhi kebutuhan energi hanya sekitar $30 \%$ dari pendapatan, selebihnya dibelanjakan untuk kebutuhan non pangan. Penyebab lain tidak adanya perbedaan proporsi pengeluaran pangan antara rumah tangga penerima KRPL dan non penerima KRPL disebabkan karena sasaran kegiatan KRPL adalah rumah tangga rawan pangan. Pada rumah tangga rawan pangan konsumsi energi rumah tangga masih rendah atau belum memenuhi angka ideal yaitu sebesar $2150 \mathrm{kkal} / \mathrm{kapita} / \mathrm{hari}$ sehingga pengeluaran rumah tangga cenderung digunakan untuk memenuhi kebutuhan konsumsi energi rumah tangga (Purwaningsih, 2010). Pada rumah tangga penerima KRPL dan non KRPL konsumsi energi masih dibawah $80 \%$ (tabel 6) sehingga rumah tangga masih menggunakan pengeluaran lebih banyak diperuntukkan untuk memenuhi kebutuhan pangan terlebih dahulu.

\section{KESIMPULAN DAN SARAN}

Berdasarkan hasil penelitian mengenai Dampak Program Kawasan Rumah Pangan Lestari Terhadap Pendapatan, dan Pengeluaran Pangan disimpulkan sebagai berikut :

a. Program KRPL memberikan dampak yang nyata terhadap peningkatan pendapatan rumah tangga. Optimalisasi pekarangan yang dilakukan melalui KRPL memberikan kontribusi sebesar 3,03 \% terhadap peningkatan pendapatan rumah tangga.

b. KRPL belum sepenuhnya memberikan kontribusi dalam menekan pengeluaran pangan rumah tangga, hal ini dikarenakan sasaran kegiatan 
KRPL adalah rumah tangga rawan pangan dengan pendapatan rendah. Pengeluaran pangan pada rumah tangga kategori tersebut cenderung mendapat porsi yang lebih besar daripada pengeluaran non pangan.

\section{DAFTAR PUSTAKA}

Badan Pusat Statistik Kabupaten Pontianak. 2014. Kabupaten Pontianak Dalam Angka 2014. Badan Pusat Statistik Kabupaten Pontianak. Mempawah

Ilham, N dan Bonar M. S. 2007. Penggunaan Pangsa Pengeluaran Pangan Sebagai Indikator Komposit Ketahanan Pangan. Pusat Analisis Sosial Ekonomi dan Kebijakan Pertanian. Bogor

Ilham. Z $\quad$ 2013. Uji $\mathrm{t}$ Dua Sampel. https://freelearningji.wordpress.com/2013/04/06/uji-t-dua-sampel/, 2013

Purwaningsih, Y. 2010. Analisis Permintaan dan Ketahanan Pangan Rumah Tangga Di Jawa Tengah. Disertasi. Universitas Gadjah Mada. Yogyakarta

Rahim, A. dan Hastuti, D. R. D. 2008. Ekonomika Pertanian (Pengantar, Teori, dan Kasus). Penebar Swadaya, Jakarta

Soekartawi. 2002. Prinsip Dasar Ekonomi Pertanian Teori dan Aplikasi. Raja Grafindo. Jakarta

Sugiyono. 2009. Metode Penelitian Bisnis. Alfabeta. Bandung 